\title{
A new family of four-ring bent-core nematic liquid crystals with highly polar transverse and end groups
}

\author{
Kalpana Upadhyaya, Venkatesh Gude, Golam Mohiuddin \\ and Rao V. S. Nandiraju*
}

Open Access

\begin{abstract}
Non-symmetrically substituted four-ring achiral bent-core compounds with polar substituents, i.e.., chloro in the bent or transverse direction in the central core and cyano in the lateral direction at one terminal end of the molecule, are designed and synthesized. These molecules possess an alkoxy chain attached at only one end of the bent-core molecule. The molecular structure characterization is consistent with data from elemental and spectroscopic analysis. The materials thermal behaviour and phase characterization have been investigated by differential scanning calorimetry and polarizing microscopy. All the compounds exhibit a wide-ranging monotropic nematic phase.
\end{abstract}

\section{Introduction}

Following the discovery of chiral and polar properties of mesomorphic bent-core compounds [1-6] the area of design, synthesis and properties of banana or bent-shaped liquid crystals (LC) has attracted considerable attention from different research groups in the past two decades. Bent-core compounds that exhibit mesomorphic properties were first reported by Vorlander [7,8] and later by Matsunaga et al. [9-11]. Later the mesophases were confirmed to be banana-type phases $[12,13]$. The important properties of these compounds, that is, the ferri- and antiferro-electric phases, chirality and non-linear properties were

recently explored [14-18] due to their possible utility in display devices. The majority of these bent-core compounds consist of five-, six- or seven-ring systems and exhibit the so-called banana phases. However, there are relatively few examples reported in the literature based on bent-core compounds exhibiting a nematic phase [6,19-24] and in particular with possible ferroelectric switching $[25,26]$ and a biaxial nematic phase [2730]. The nematic phases exhibited by bent-core compounds are distinctly different from the nematic phases exhibited by rodlike (calamitic) molecules. 
Recent reports of a nematic phase composed of SmC-type cybotactic clusters [20-25] particularly in bent-core compounds followed by the optical observation of a biaxial nematic phase [27] motivated the design and synthesis of new bent-core compounds with different functional moieties to exhibit nematic phases. However, there are relatively few examples reported in the literature based on four-ring bent-core or nonlinear molecular architectures [31-39]. Furthermore, the introduction of a polar cyanobiphenyl moiety in bent-core systems exhibiting mesomorphism is rare [22].

\section{Design of the molecule}

The recent experimental support in favour of a biaxial nematic phase that is exhibited by bent-core mesogens composed of two rod-like mesogenic wings coupled to a central linking moiety has been debated very well. The central linking moiety is mainly thiadiazole or oxadiazole derivatives with a large transverse dipole and an obtuse bent angle between the two arms. This represents a banana or V-shaped molecule composed of two uniaxial arms with a central transverse dipole. The study of the influence of dipole-dipole correlations on the stability of the biaxial nematic phase, in the two-particle-cluster approximation $[40,41]$, revealed that (a) the polar-molecular-shape correlations between neighbouring molecules substantially favour the stabilization of biaxial nematic phases, and (b) the electrostatic interactions between permanent transverse dipoles of bent-core molecules also significantly stabilize the biaxial nematic phases. The introduction of a 2-chloro group in the 1,3-disubstituted phenyl ring of a bent-core molecular architecture can generate an obtuse bond angle of $\sim 145^{\circ}$, which gives rise to an increase in bend angle as well as a strong dipole in the bending direction. The reduced bend from 120 to $\sim 145^{\circ}$ of the 1,3-phenyl moiety by the introduction of a chloro group in the 2-position and with the decrease in the number of rings from five or more to four in the molecular unit, places these compounds at the borderline between classical rodlike LCs and bent-core mesogens. The four-ring molecules can also be recognised as true hockey-stick model molecules. Further replacement of an azobenzene or salicylideneimine or phenylbenzoate unit in one of the arms of the bent molecule by a polar cyanobiphenyl moiety lends stiffness to the molecule with a strong dipole moment in the lateral direction. The realization of such a molecular architecture leads to a reduction in rotational disorder as well as a strong dipole in the bent direction. If molecular interactions are strong enough then the molecular structure can promote polar biaxial nematic phases.

In this study, we aimed to combine the lateral dipole in the form of a cyanobiphenyl moiety as one of the arms of the bent-core molecule, while the central bent core possesses a chloro substituent projected at a location inside the molecular core to represent the transverse dipole. The other end of the molecule is linked to 4- $n$-alkoxysalicylaldehyde through an imine moiety, which actually seems superior to the benzylidene aniline core and is more stable towards hydrolysis due to intramolecular hydrogen bonding. We report here the synthesis and characterization of the compounds 1a-1f (Scheme 1) by elemental analysis, spectroscopic data, polarized optical microscopy (POM) and differential scanning calorimetry (DSC).

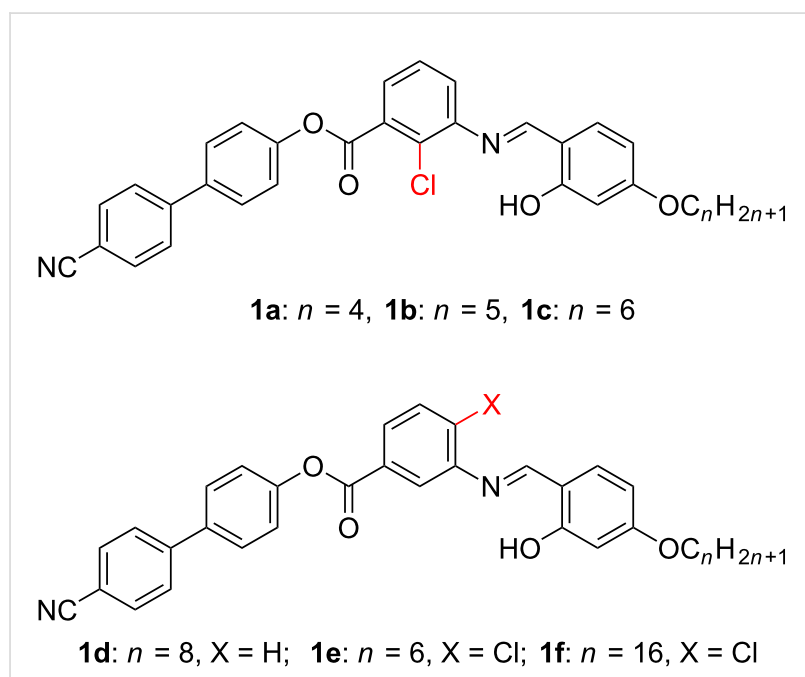

Scheme 1: Molecular structures of the investigated four-ring bent-core compounds 1a-1f.

\section{Results and Discussion Synthesis and characterization}

Here we adopted a very simple and straightforward synthetic methodology for the synthesis of these materials exhibiting a nematic phase. The non-symmetric four-ring molecules possess an alkoxy chain attached at only one end of the bent-core molecule, while the other arm ends with a highly polar cyano group. The end cyano group in one of the arms of 1a-1c contributes to the large dipole moment. In highly polar calamitic cyanobiphenyl compounds $[42,43]$ as well as in bent-core compounds possessing an end cyano moiety [44-48] the antiparallel short-range order was confirmed. The highly polarizable aromatic parts, which have conjugated electrons, contribute to the anisotropic dispersion potential between them. This is due to the arrangement of two neighbouring molecules in an antiparallel orientation and, hence, the aromatic moieties of the two molecules overlap. This contributes to the strong attractive interaction between them.

The molecule consists of two linkages between the three aromatic fragments, giving an ortho-hydroxy benzylidene moiety, a benzoic acid ester moiety, and a biphenyl residue. The salicylidene linkage instead of the unsubstituted benzylidene 
linkage was preferred due to the presence of the ortho-hydroxy group, which enhances the transverse dipole moment as well as the stability of the imines through intramolecular H-bonding to overcome the hydrolytic instability of the molecules towards moisture. The bent-core platform was designed from 3-substituted 2-chlorobenzoic acid and then coupled with 4'-hydroxy[1,1'-biphenyl]-4-carbonitrile to achieve the target compound. The chloro substituent creates a strong transverse dipole moment, which may favour polar ordering.

Commercially available 2-chloro-3-nitrobenzoic acid (2), is reduced with $5 \% \mathrm{Pd} / \mathrm{C}$ to yield 2-chloro-3-aminobenzoic acid (3). 4-n-Alkoxysalicylaldehydes 5a-5e were synthesized following the procedures reported earlier [38,39]. 2-Chloro-3aminobenzoic acid (3) was then condensed with alkoxysalicylaldehydes $\mathbf{5 a}-5 \mathbf{c}$ to yield the corresponding 3-(4- $n$-alkoxysalicylidene)amino)-2-chlorobenzoic acids $\mathbf{6 a - 6 c}$. Coupling of these acids with 4'-hydroxy-[1,1'-biphenyl]-4-carbonitrile in the presence of $N, N^{\prime}$-dicyclohexylcarbodiimide (DCC) and a catalytic amount of dimethylaminopyridine (DMAP) produced the desired products 4'-cyanobiphenyl-4-yl 2-chloro-3-[((2hydroxy-4- $n$-alkoxybenzylidene)amino)benzoates 1a-1c. To make a comparison with the mesomorphic 1a-1c, other compounds 1d-1f were prepared following the same procedure adopted for 1a by using the appropriate reagents as outlined in Scheme 2.

The chemical structures of the final compounds $\mathbf{1}$ were confirmed by spectral techniques and elemental analysis. The analytical data are in good agreement with their chemical structures. The main observed FTIR peaks confirmed the intramolecular H-bonding of $\mathrm{OH}^{\cdots} \mathrm{N}$ at $3184 \sim 3186 \mathrm{~cm}^{-1}$, CN stretching at $2220 \mathrm{~cm}^{-1}, \mathrm{C}=\mathrm{O}$ stretching of an ester at $1737 \sim 1741 \mathrm{~cm}^{-1}$, $\mathrm{C}=\mathrm{N}$ stretching of an imine at $1602 \sim 1606 \mathrm{~cm}^{-1}, \mathrm{C}=\mathrm{C}$ stretching of an aromatic ring $1490 \mathrm{~cm}^{-1}$ and $\mathrm{C}-\mathrm{O}-\mathrm{C}$ stretching of an ester at $\sim 1290$ and $\sim 1170 \mathrm{~cm}^{-1}$. The importance of the resor-<smiles>O=C(O)c1cccc([N+](=O)[O-])c1Cl</smiles>

2<smiles>[I-][I-]</smiles><smiles>Nc1cccc(C(=O)O)c1Cl</smiles>

3<smiles>CCOc1ccc(/C=N/c2cccc(C(=O)O)c2Cl)c(O)c1</smiles>

6a: $n=4$

6b: $n=5$

6c: $n=6$<smiles>O=Cc1ccc(O)cc1O</smiles>

4<smiles>CCCCCCCOc1ccc(C=O)c(O)c1</smiles>

5a: $n=4$

5b: $n=5$

5c: $n=6$

5d: $n=8$

5e: $n=16$

6

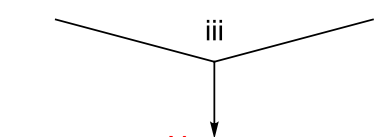<smiles>[X]c1ccc(C(=O)O)cc1N</smiles>

7a: $X=\mathrm{H}$

7b: $X=\mathrm{Cl}$<smiles>[X]c1ccc(C(=O)O)cc1/N=C/c1ccc(OCC[18F])cc1O</smiles>

8a: $n=8 ; \mathrm{X}=\mathrm{H}$

8b: $n=6 ; \mathrm{X}=\mathrm{Cl}$

8c: $n=16 ; \mathrm{X}=\mathrm{Cl}$

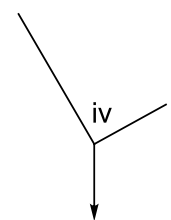

1a: $n=4$
1b: $n=5$
1c: $n=6$
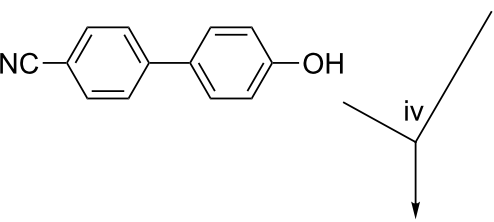

1d: $n=8 ; \mathrm{X}=\mathrm{H}$,

1e: $n=6 ; \mathrm{X}=\mathrm{Cl}$,

1f: $n=16 ; \mathrm{X}=\mathrm{Cl}$

Scheme 2: Synthetic details of the compounds 1a-1f. Reagents and conditions: i. $5 \% \mathrm{Pd} / \mathrm{C}, \mathrm{H}_{2}$, EtOAc stirring, 48 h; ii. dry acetone, $\mathrm{KHCO} 3$, $\mathrm{C}_{n} \mathrm{H}_{2 n+1} \mathrm{Br}(n=4,5,6,8,16) ; \mathrm{KI}, \Delta, 48 \mathrm{~h}$; iii. abs $\mathrm{EtOH}, \mathrm{AcOH}, \Delta, 6 \mathrm{~h}$; iv. DCC, DMAP, DCM, stirring, $48 \mathrm{~h}$. 
cylidene aniline core, present in calamitic ferroelectric liquid crystals [49-53], apparently seems superior to that of the benzylidene aniline core with respect to mesogenicity to exhibit an anticlinic bilayer smectic phase $\left(\mathrm{SmAP}_{\mathrm{A}}\right)$, and to its stability towards hydrolysis.

The mesomorphic behaviour of compounds 1a-1c was characterized by polarized optical microscopy (POM), and the samples, on cooling from the isotropic phase, exhibited marble or highly birefringent two-brush Schlieren textures (Figure 1) in the nematic phase. This indicates a predominantly homogeneous alignment of the sample with the nematic director being on average parallel to the substrate surface. On further cooling they exhibit a slow transition to a homeotropic alignment initially over small areas, which subsequently spread to the entire area under observation, as shown in Figure 1. The strong attraction between rigid cores augmented by intermolecular interactions due to end-polar moieties as well as the bent shape can promote the nearest neighbour aggregations and hence the formation of cybotactic clusters in the nematic phase [23,27]. Although the presence of cybotactic clusters in the nematic phase can clearly be demonstrated by small-angle X-ray studies due to their small size, such clusters cannot be observed by POM. Hence the dark regions of the optical texture (homeotropic texture, Figure 1b) can be explained by the growth of cybotactic clusters followed by the transformation to a homeotropic orientation [21]. The homeotropic regions exhibit transient birefringent textures either by shearing or tapping.

The phase transitions are confirmed by differential scanning calorimetry (DSC). The thermodynamic data are presented in Table 1. A representative DSC trace obtained during the initial heating and cooling cycles scanned at a rate of $10 \mathrm{~K} \mathrm{~min}^{-1}$ for $1 \mathbf{c}$ is presented in Figure 2. The nematic-isotropic phase-transition enthalpies are of the order of $0.15 \sim 0.29 \mathrm{~kJ} / \mathrm{mol}$ for $\mathbf{1 a - 1 c}$ and are in agreement with the reported enthalpies at the N-I phase transition exhibited by bent-core compounds.

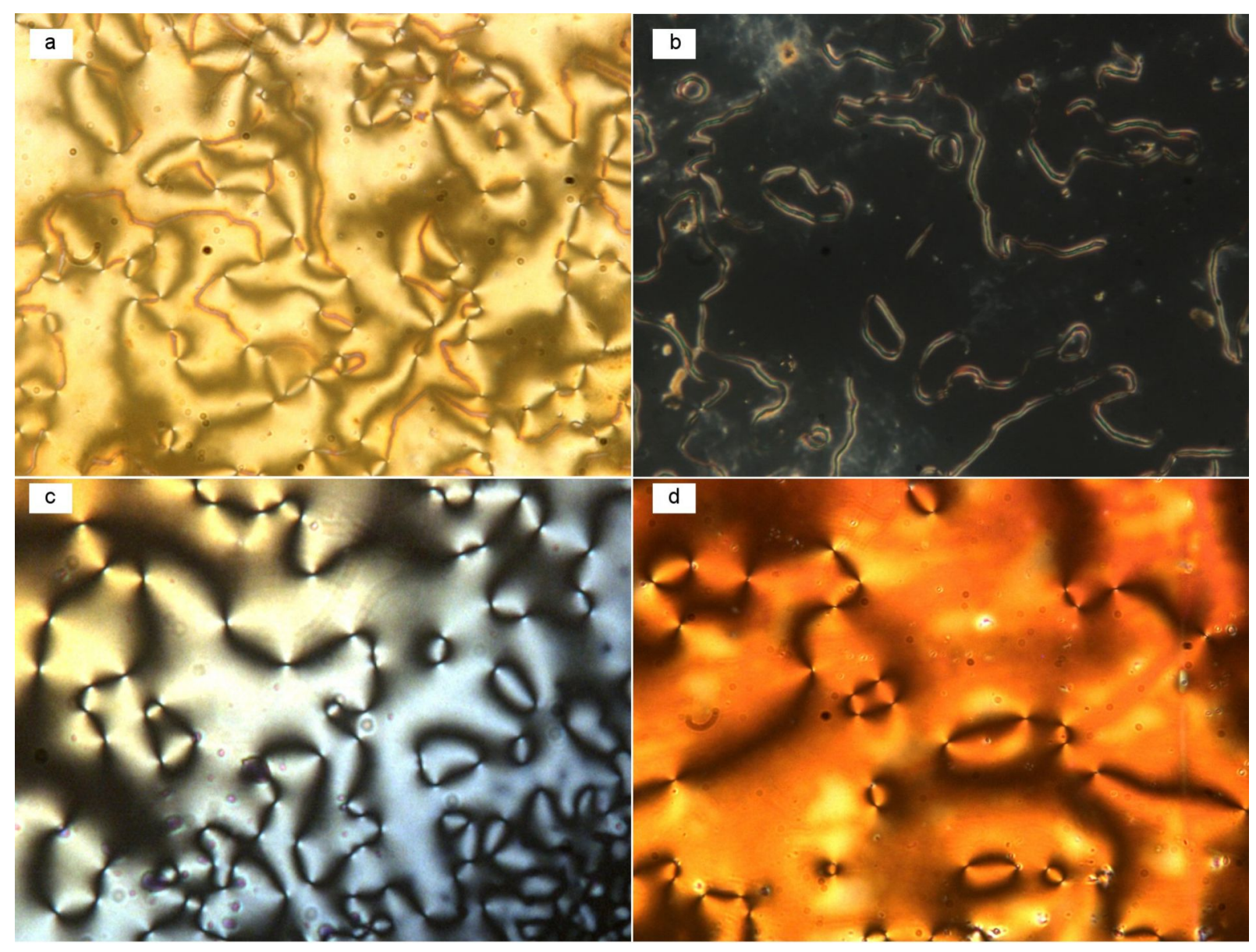

Figure 1: Microphotographs of compounds $1 \mathbf{b}$ and $1 \mathrm{c}$ in the nematic phase during the cooling cycle. (a) Birefringent Schlieren texture of $1 \mathbf{b}$ at $145{ }^{\circ} \mathrm{C}$; (b) disappearance of birefringence and transformation to the homeotropic texture of $\mathbf{1 b}$ at $122^{\circ} \mathrm{C}$; (c) two-brush-defect Schlieren texture of $1 \mathrm{c}$ at $161^{\circ} \mathrm{C}$ from I-N transition; (d) Schlieren texture with increased birefringence at $156^{\circ} \mathrm{C}$. 
Table 1: Phase-transition temperatures $\left({ }^{\circ} \mathrm{C}\right)$ of the compounds $1 \mathrm{a}-\mathbf{1 f}$, recorded for second heating (first row) and second cooling (second row) cycles at $10^{\circ} \mathrm{C} / \mathrm{min}$ from DSC and confirmed by polarized optical microscopy. The enthalpies $(\Delta H$ in $\mathrm{kJ} / \mathrm{mol})$ are presented in parentheses.

\section{Compound Phase transition temperatures (enthalpy)}

$\begin{array}{ll}\text { 1a } & \text { Cr 176.5 (56.1) Iso } \\ & \text { Cr 45.1(2.05) N 143.3 (0.158) Iso } \\ \text { 1b } & \text { Cr 176.8(79.7) Iso } \\ & \text { Cr 78.8 (41.6) N 162.8 (0.227) Iso } \\ \text { 1c } & \text { Cr 164.4 (58.8) Iso } \\ & \text { Cr } 87.6(63.5) \text { N 161.3 (0.290) Iso } \\ \text { 1d } & \text { Cr 144 Iso } \\ \text { 1e } & \text { Cr 189 Iso } \\ \text { 1f } & \text { Cr 148 Iso }\end{array}$

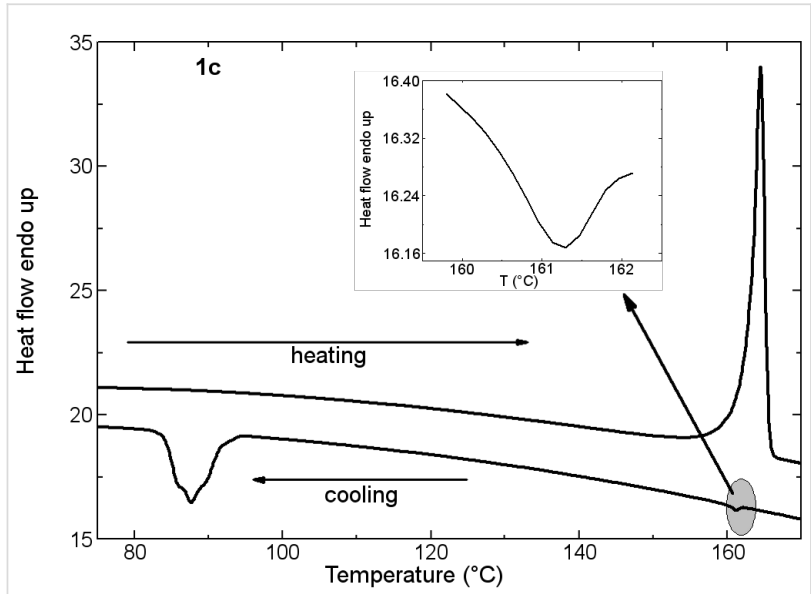

Figure 2: DSC trace of 1c obtained during initial heating and cooling cycles scanned at a rate of $10 \mathrm{~K} / \mathrm{min}$.

To gain an understanding of the structure-property relationship we synthesized other homologues of the same core with variations in the position of the chloro substituent, or without any substituent. The unsubstituted homologue 1d with a terminal $n$-octyloxy chain did not exhibit mesomorphism. Similarly, in cases where the chloro substituent was shifted to the 4-position, the compound 1e, with a $n$-hexyloxy terminal chain, or its higher homologue with a $n$-hexadecyloxy chain 1f, did not exhibit mesomorphism. It is surprising that the aspect ratio of all compounds is almost the same, but the compounds with a transverse chloro substituent exhibit monotropic nematic phases, while the other homologues with a lateral dipole did not exhibit mesomorphism. In general, the monotropic behaviour was often considered as kinetically unstable, and hence it could occur when the aspect ratio of the molecule was not appropriate. Further investigations are in progress to understand the reasons for such behaviour.
The size of the bent cores, reflected by the number of rings; lateral or transverse substituents, which promote lateral or transverse interactions; and the length of terminal aliphatic chains, which strongly influences the segregation of the aromatic and aliphatic regions, all contribute to the formation of banana mesomorphism, in particular the layered phases. The bent shape and size of the bent core with a lateral polar substituent $[21,22,54-57]$ leads to the reduction of the rotational disorder of the molecules around their long axes to promote nematic phases. However, for short-chain members of a homologous series ( $n$-butyl to $n$-hexyl units), the microsegregation of incompatible aromatic and aliphatic moieties of the molecules is weak, and hence nematic phases can be found rather than the layered phases. Furthermore, they promote nearest-neighbour aggregations, such as the cybotactic clusters in the nematic phase, which are also augmented by intermolecular interactions due to polar end moieties as well as the bent shape, reflecting the textures with homeotropic orientation. The chloro substituent in the transverse position of the bent molecule promoted mesomorphism. When the size of the bent core is reduced to four rings, the chloro substitution in the lateral position possibly contributes to a weakening of lateral interactions and hence does not promote the necessary molecular interactions to exhibit mesomorphism. The repulsion between the transverse polar chloro substituent in $\mathbf{1 a - 1 c}$ and the adjacent ester or imine linkages leads to a torque exercised on the wing of the bent molecule and, hence, leads to an increase in the bending angle. An increase in bending angle may contribute to increased van der Waals interactions and dispersion forces and, hence, promote mesomorphism during the cooling cycle in these compounds. The absence of mesomorphism in $\mathbf{1 e}$ and $\mathbf{1 f}$ may be attributed to possibly weakened lateral interactions and increased intermolecular spacing between molecules.

\section{Density functional theory calculations}

The quantum mechanical calculations of molecular properties in the gas phase were performed by using density functional theory (DFT) [58] employing the combination of the Becke (3-parameter)-Lee-Yang-Parr (B3LYP) hybrid functional and the $6-31 \mathrm{~g}(\mathrm{~d}, \mathrm{p})$ basis set using the Gaussian 09 package, to obtain the information related to molecular conformation, bend angle, dipole moment, molecular polarizability, and asymmetry parameter of all the compounds 1a-1f. Full geometry optimizations were carried out without imposing any constraints [58]. Spin-restricted DFT calculations were carried out in the framework of the generalized gradient approximation (GGA) by using the B3LYP hybrid functional, exchange-correlation functional and the 6-31G(d,p) standard basis set $[59,60]$ due to its successful application to larger organic molecules, as well as hydrogen-bonded systems in the past [61-63] and bent-core molecules [30,64-67] recently. 


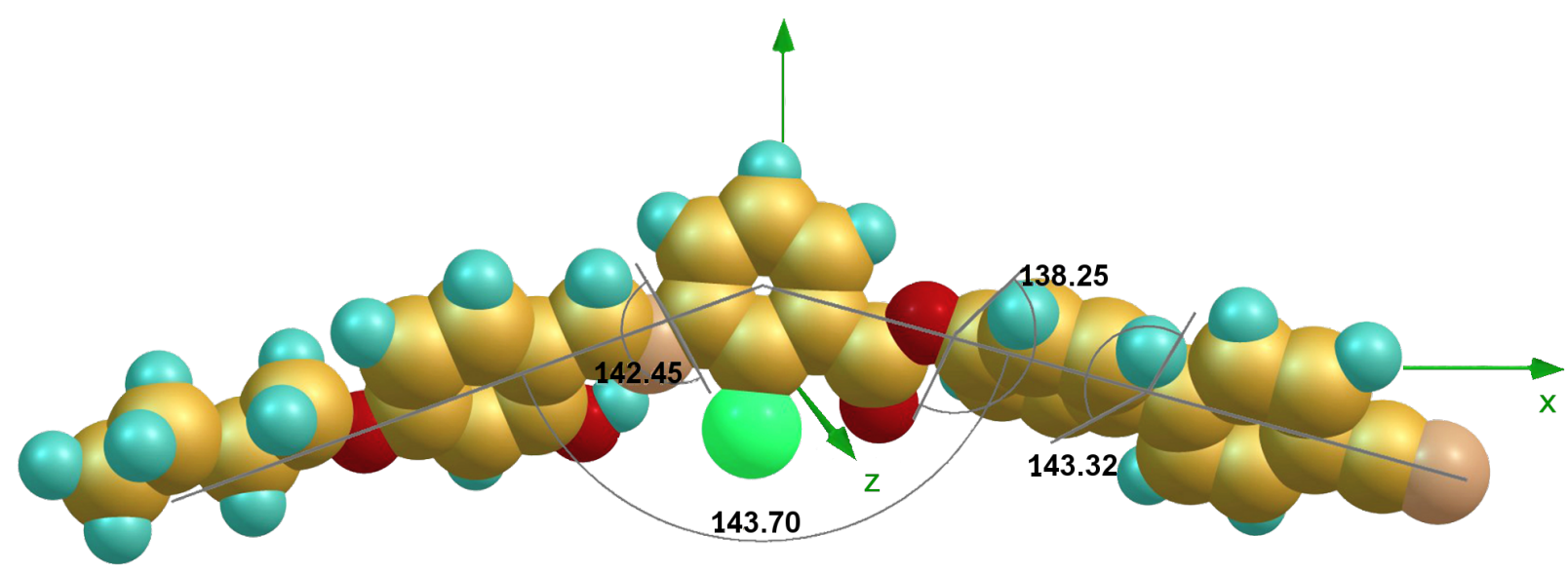

Figure 3: Molecular structure of 1a optimized at the DFT level. The bent angle is $143^{\circ}$, and the three dihedral angles indicated the out-of plane adjacent phenyl rings.

The three dihedral angles between the first phenyl and central phenyl moieties with imine linkage, central ring and first biphenyl ring with ester linkage and between the two phenyl rings of biphenyl moiety are $142^{\circ}, 138^{\circ}$ and $143^{\circ}$, respectively (Figure 3), reflecting the absence of coplanarity of the phenyl rings in the molecule. The analysis shows that the bend angle is approximately $143^{\circ}$ for all mesogens and is influenced by the transverse chloro substituent in the 2-position of the central phenyl ring. The bending angle for the compound $\mathbf{1 d}$ is $138^{\circ}$ and for 1e and $\mathbf{1 f}$ is $135^{\circ}$. This may have contributed to an increase in intermolecular separation and thereby did not promote mesomorphism. For all the mesogens, the dipole points almost in the lateral direction with respect to molecular long axis.

All molecules possess a considerably larger dipole along the molecule's long axis ( $x$ axis). The results of bending angles and dipole-moment components are summarized in Table 2 and Table 3 for all the molecules. Furthermore, the polarizability component $\alpha_{X X}$ is largest along the longitudinal $x$ axis (Table 3), which indicates a more dispersed electron cloud. Such a dispersed electron cloud leads to a larger amount of surface contact. The asymmetry parameter $\eta=\left[\left(\alpha_{\mathrm{yy}}-\alpha_{\mathrm{zz}}\right) /\left(\alpha_{\mathrm{xx}}\right.\right.$ $\left.\left.-\alpha^{\text {iso }}\right)\right] \sim 0.20 \pm 0.02,\left(\alpha_{x x}, \alpha_{y y}\right.$, and $\alpha_{z z}$ being the principle component of the polarizability tensor and $\alpha^{\text {iso }}=\left(\alpha_{\mathrm{xx}}+\alpha_{\mathrm{yy}}+\right.$ $\left.\alpha_{\mathrm{zz}}\right) / 3$ ) is rather small reflecting the importance of the large bending angle. However, it decreases with the increase in endchain length.

\section{Conclusion}

Non-symmetric four-ring bent-core hockey-stick-shaped molecules have been designed and synthesized, and mesomorphism has been confirmed in these polar molecular architectures. The
Table 2: DFT-calculated bend angle $\Theta$, dipole-moment components $\left(\mu_{x}, \mu_{y}, \mu_{z}\right)$, modulus $(\mu)$, and angle $\gamma$, formed with respect to the longitudinal axis $x$ as shown in Figure 3 . $^{a}$

Compound Dipole moment (Debye) Bend angle $\left({ }^{\circ}\right)$

\begin{tabular}{llllll}
\hline & $\mu_{x}$ & $\mu_{y}$ & $\mu_{z}$ & $\mu_{\text {resultant }}{ }^{b}$ \\
\hline 1a & 8.60 & 5.97 & 2.47 & 10.76 & 143 \\
1b & 8.63 & 5.91 & 2.60 & 10.78 & 143 \\
1c & 8.59 & 5.98 & 2.77 & 10.83 & 143 \\
1d & 8.30 & 5.57 & 2.53 & 10.31 & 138 \\
1e & 7.14 & 3.39 & 3.01 & 8.46 & 135 \\
1f & 6.76 & 3.78 & 3.49 & 8.50 & 135
\end{tabular}

aThe values relative to angles and dipole moment are expressed in degree $\left({ }^{\circ}\right)$ and Debye (D), respectively. ${ }^{b} \mu_{\text {resultant }}=\left(\mu_{x}{ }^{2}+\mu_{y}{ }^{2}+\right.$ $\left.\mu_{z}^{2}\right)^{1 / 2}$.

Table 3: DFT calculated principal polarizability components $\left(\alpha_{x x}, a_{y y}\right.$, $\left.a_{z z}\right)$, isotropic polarizability $\alpha^{\text {iso }}=\left(\alpha_{x x}+\alpha_{y y}+\alpha_{z z}\right) / 3$, polarizability anisotropy $\Delta \alpha=\left[\alpha_{x x}-\left(\alpha_{y y}+\alpha_{z z}\right) / 2\right]$, and asymmetry parameter, $\eta=$ $\left[\left(\alpha_{y y}-\alpha_{z z}\right) /\left(\alpha_{x x}-\alpha^{\text {iso }}\right)\right]$. Parameters are relative to the molecular polarizability tensor in the Cartesian reference frame. ${ }^{a}$

\begin{tabular}{lcccccc} 
Compound & $\alpha_{x x}$ & $\alpha_{y y}$ & $\alpha_{z z}$ & $\alpha^{\text {iso }}$ & $\Delta \alpha$ & $\eta_{\alpha}$ \\
\hline 1a & 780 & 301 & 222 & 435 & 518 & 0.228 \\
1b & 800 & 308 & 234 & 447 & 533 & 0.208 \\
1c & 817 & 315 & 245 & 459 & 537 & 0.195 \\
1d & 838 & 367 & 213 & 473 & 548 & 0.420 \\
1e & 783 & 360 & 218 & 454 & 494 & 0.431 \\
1f & 929 & 460 & 316 & 568 & 441 & 0.398 \\
\hline
\end{tabular}

aAll polarizability components and the anisotropy parameter are calculated in $(\mathrm{bohr})^{3}$ (with 1 bohr $=0.52917 \AA$ ). 
thermal behaviour of the novel four-ring compounds has been investigated by DSC and POM. The compounds derived from transverse and terminal polar substituents in the bent-core molecules exhibited monotropic nematic phases, while compounds with lateral and terminal polar substituents did not show mesomorphism. A preliminary insight into the structure-property relationships of bent-core molecules revealed that the mesophase behaviour is strongly influenced by the number of rings [21,22,35,54-57], the type and direction of linking groups [33-39], the nature and position of terminal and transverse substituents [39], and the type and length of the terminal chains [39]. As these results are of importance in relation to current commercial requirements for a range of stable bent-core mesogens exhibiting a wide spectrum of physical properties, further experimental studies, i.e., examining birefringence, elastic constants, viscosity, and electro-optical characteristics, are in progress in fundamental and applied research. Attempts to realize the enantiotropic mesomorphism in such compounds at ambient temperature by a modification of the substituents with different molecular topologies are currently in progress.

\section{Experimental}

All the chemicals were procured from M/s Alfa Aesar or Aldrich or Tokyo Kasei Kogyo Co. Ltd. The solvents and reagents are of $\mathrm{AR}$ grade and were distilled and dried before use. Micro analysis of $\mathrm{C}$ and $\mathrm{H}$ elements were determined on Carlo-Erba 1106 elemental analyzer. IR spectra were recorded on Shimadzu IR Prestige-21, FTIR-8400S $\left(v_{\max }\right.$ in $\left.\mathrm{cm}^{-1}\right)$ as $\mathrm{KBr}$ disks. The ${ }^{1} \mathrm{H}$ nuclear magnetic resonance spectra were recorded on NMR spectrometers (Bruker DPX-400 $400 \mathrm{MHz}$ or JEOL AL300 FTNMR $300 \mathrm{MHz}$ ) in $\mathrm{CDCl}_{3}$ solution (chemical shift $\delta$ in parts per million) with TMS as internal standard. The liquid-crystalline properties were observed and characterized by polarizing microscopy (Nikon optiphot-2-pol with an attached hot and cold stage HCS302, with STC200 temperature controller configured for HCS302 from INSTEC Inc. USA). The phase transition temperatures and associated enthalpies were recorded on differential scanning calorimetry (PerkinElmer Pyris-1 system) with a heating/cooling rate of $10^{\circ} \mathrm{C} / \mathrm{min}$.

4-n-Butyloxy-2-hydroxybenzaldehyde (5a): In the synthesis of 4-n-butyloxy-2-hydroxy-benzaldehyde (Scheme 2), monoalkylation was performed by using a modification of the literature procedure to improve the product yield. 2,4-Dihydroxybenzaldehyde (4, $10 \mathrm{~g}, 72.4 \mathrm{mmol}), 1$-bromobutane $(10.3 \mathrm{~mL}, 75 \mathrm{mmol}), \mathrm{KHCO}_{3}(6.30 \mathrm{~g}, 75 \mathrm{mmol})$ and $\mathrm{KI}$ (catalytic amount) were mixed in dry acetone $(250 \mathrm{~mL})$ and then the mixture was heated under reflux for $48 \mathrm{~h}$. It was then filtered hot to remove the insoluble solid. The warm solution was neutralized by the addition of dilute $\mathrm{HCl}$, then extracted twice with $\mathrm{CHCl}_{3}(100 \mathrm{~mL})$. The combined extracts were concentrated to give a purple solid. The product was purified by column chromatography using silica gel (60-120 mesh) eluting with a mixture of chloroform and hexane $(\mathrm{V} / \mathrm{V}, 1 / 1)$ followed by evaporation of solvent. It gave the product as a pale yellow liquid. Yield $=10.6 \mathrm{~g}(70 \%)$; IR $v_{\max }: 1666\left(v_{\mathrm{C}=\mathrm{O}}\right.$, aldehyde $)$, 3449 ( $v_{\mathrm{O}-\mathrm{H}}, \mathrm{H}$-bonded $) \mathrm{cm}^{-1} ;{ }^{1} \mathrm{H}$ NMR $\left(300 \mathrm{MHz}, \mathrm{CDCl}_{3}\right) \delta$ $11.41(\mathrm{~s}, 1 \mathrm{H},-\mathrm{OH}), 9.66(\mathrm{~s}, 1 \mathrm{H},-\mathrm{CH}=\mathrm{O}), 7.40(\mathrm{~d}, 1 \mathrm{H}, J=$ $8.8 \mathrm{~Hz}, \operatorname{ArH}), 6.51$ (d, 1H, $J=8.9 \mathrm{~Hz}, \operatorname{ArH}), 6.61(\mathrm{~d}, 1 \mathrm{H}, J=$ $2.8 \mathrm{~Hz}, \mathrm{ArH}), 4.03\left(\mathrm{t}, 2 \mathrm{H}, J=7.8 \mathrm{~Hz},-\mathrm{O}-\mathrm{CH}_{2}-\right) ; 1.65(\mathrm{q}, 2 \mathrm{H}, J$ $\left.=6.6 \mathrm{~Hz},-\mathrm{OCH}_{2}-\mathrm{CH}_{2}-\right), 1.38-1.20\left(\mathrm{~m}, 4 \mathrm{H},-\left(\mathrm{CH}_{2}\right)_{2}-\right), 0.88(\mathrm{t}$, $\left.3 \mathrm{H}, J=6.6 \mathrm{~Hz},-\mathrm{CH}_{3}\right)$.

The other compounds $\mathbf{5 b}-\mathbf{5 e}$ had been synthesized following the procedure adopted for $\mathbf{5 a}$.

2-Chloro 3- $\mathrm{N}$-(4-n-butyloxysalicylidene)aminobenzoic acid (6a): An ethanolic solution of 2-chloro-3-aminobenzoic acid (3, $0.51 \mathrm{~g}, 3 \mathrm{mmol})$ was added to an ethanolic solution $(20 \mathrm{ml})$ of 4 - $n$-butyloxysalicylaldehyde (5a, $0.58 \mathrm{~g}, 3 \mathbf{m m o l}$ ). The mixture was heated under reflux with a few drops of glacial acetic acid as catalyst for $6 \mathrm{~h}$ to yield the yellow-coloured Schiff's base. The precipitate was collected by filtration from the hot solution and recrystallized several times from absolute ethanol to give a pure compound. Yield $=0.8 \mathrm{~g}(84 \%)$; IR $v_{\max }: 1618\left(v_{\mathrm{CH}=\mathrm{N}}\right.$, imine $), 1719\left(v_{\mathrm{C}=\mathrm{O}}\right.$, acid $), 3425\left(v_{\mathrm{O}-\mathrm{H}}, \mathrm{H}\right.$-bonded $) \mathrm{cm}^{-1}$; ${ }^{1} \mathrm{H}$ NMR (400 MHz, $\mathrm{CDCl}_{3}$ ): $\delta 13.49$ (s, $\left.1 \mathrm{H},-\mathrm{OH}\right), 9.99$ (s, $1 \mathrm{H}$, $-\mathrm{COOH}), 8.35$ (s, 1H, $-\mathrm{CH}=\mathrm{N}-), 7.88$ (d, $J=8.4 \mathrm{~Hz}, 1 \mathrm{H}, \mathrm{ArH})$, $7.33(\mathrm{t}, J=8.0 \mathrm{~Hz}, 1 \mathrm{H}, \mathrm{ArH}), 7.46(\mathrm{~d}, J=8.4 \mathrm{~Hz}, 1 \mathrm{H}, \mathrm{ArH})$, 7.29 (d, $J=7.8 \mathrm{~Hz}, 1 \mathrm{H}, \mathrm{ArH}), 6.98(\mathrm{~d}, J=8.4 \mathrm{~Hz}, 1 \mathrm{H}, \mathrm{ArH})$, $6.43(\mathrm{~s}, 1 \mathrm{H}, \mathrm{ArH}), 4.01\left(\mathrm{t}, J=7.8 \mathrm{~Hz}, 2 \mathrm{H},-\mathrm{OCH}_{2}-\right), 1.56$ (q, $\left.2 \mathrm{H},-\mathrm{CH}_{2}-\right), 1.29-1.21\left(\mathrm{~m}, 2 \mathrm{H},-\mathrm{CH}_{2}\right), 0.88(\mathrm{t}, 3 \mathrm{H}, J=7.8 \mathrm{~Hz}$, $\left.-\mathrm{CH}_{3}\right)$.

The compounds $\mathbf{6 b}, \mathbf{6 c}, \mathbf{8 a}-\mathbf{8 c}$ were synthesized following the procedure adopted for $\mathbf{6 a}$, with appropriate starting materials.

4'-Cyano-[1,1'-biphenyl]-4-yl 3-((4-butoxy-2-hydroxybenzylidene)amino)-2-chlorobenzoate (1a): $N, N$-dicyclohexylcarbodiimide (DCC, $0.206 \mathrm{~g}, 1.0 \mathrm{mmol}$ ) was added all at once to a stirred mixture of 3-((4-n-butyloxy-2-hydroxybenzylidene)amino)-2-chlorobenzoic acid (0.35 g, $1.0 \mathrm{mmol})$, 4'-hydroxy-[1,1'-biphenyl]-4-carbonitrile (0.195 g, $1.0 \mathrm{mmol})$ and a catalytic amount of $N, N$-dimethylaminopyridine (DMAP) dissolved in dry dichloromethane (DCM) $(50 \mathrm{~mL})$ in a roundbottom two-neck flask flushed with $\mathrm{N}_{2}$, arranged with a tefloncoated magnetic stirrer at room temperature. The reaction mixture was stirred for $48 \mathrm{~h}$ at room temperature (completion of reaction was confirmed by TLC analysis) followed by the removal of dicyclohexylurea by filtration. Evaporation of the solvent in vacuum gave the crude product, which was washed with hot ethanol, followed by recrystallization from ethanol/ 
ethyl acetate to obtain the pure product $1 \mathrm{a}$ as a yellow solid. Yield $=0.30 \mathrm{~g}(58 \%)$; IR (KBr) $v_{\text {max }}: 3186,2951,2864,2221$, $1741,1604,1512,1490,1384,1344,1288,1220,1192,1163$, 1107, $744 \mathrm{~cm}^{-1}$; ${ }^{1} \mathrm{H}$ NMR (400 MHz, $\left.\mathrm{CDCl}_{3}\right) \delta 13.46(\mathrm{~s}, 1 \mathrm{H}$, $-\mathrm{OH}), 8.55(\mathrm{~s}, 1 \mathrm{H},-\mathrm{CH}=\mathrm{N}-), 7.86(\mathrm{dd}, J=2.0,7.6 \mathrm{~Hz}, 1 \mathrm{H}$, $\mathrm{ArH}), 7.75$ (dd, $J=2.4 \mathrm{~Hz}, 8.8 \mathrm{~Hz}, 2 \mathrm{H}, \mathrm{ArH}), 7.69$ (dd, $J=2.0$, $8.8 \mathrm{~Hz}, 2 \mathrm{H}, \mathrm{ArH}), 7.64$ (dd, $J=2.4 \mathrm{~Hz}, 8.8 \mathrm{~Hz}, 2 \mathrm{H}, \mathrm{ArH}), 7.46$ (d, $J=8.0 \mathrm{~Hz}, 1 \mathrm{H}, \mathrm{ArH}), 7.42$ (d, $J=8.0 \mathrm{~Hz}, 1 \mathrm{H}, \mathrm{ArH}), 7.38$ $(\mathrm{dd}, J=2.4,8.0 \mathrm{~Hz}, 1 \mathrm{H}, \mathrm{ArH}), 7.31(\mathrm{dd}, J=2.0,7.6 \mathrm{~Hz}, 2 \mathrm{H}$, $\operatorname{ArH}), 6.52(\mathrm{dd}, J=2.4 \mathrm{~Hz}, 7.2 \mathrm{~Hz}, 2 \mathrm{H}, \mathrm{ArH}), 4.02(\mathrm{t}, J=$ $\left.6.4 \mathrm{~Hz}, 2 \mathrm{H},-\mathrm{OCH}_{2}-\right), 1.83-1.76\left(\mathrm{~m}, 2 \mathrm{H},-\left(\mathrm{CH}_{2}\right)-\right), 1.55-1.46$ $\left(\mathrm{m}, 2 \mathrm{H},-\left(\mathrm{CH}_{2}\right)-\right), 0.98\left(\mathrm{t}, 3 \mathrm{H},-\mathrm{CH}_{3}\right)$; Anal. calcd for $\mathrm{C}_{31} \mathrm{H}_{25} \mathrm{ClN}_{2} \mathrm{O}_{4}$ : C, 70.92; H, 4.80; found: C, 70.61; H, 4.75.

For the synthesis of $\mathbf{1 b}-\mathbf{1 f}$, the same experimental procedure as described for the preparation of 1a (with appropriate chemicals as detailed in Scheme 2) was followed to obtain the yellow solids. Yield of $\mathbf{1 b}=0.32 \mathrm{~g}, 60 \%$, yield of $\mathbf{1 c}=0.30 \mathrm{~g}, 55 \%$; yield of $1 \mathbf{d}=0.31 \mathrm{~g}, 56 \%$; yield of $1 \mathrm{e}=0.33 \mathrm{~g}, 61 \%$; yield of $\mathbf{1 f}$ $=0.45 \mathrm{~g}, 65 \%$.

4'-Cyano-[1,1'-biphenyl]-4-yl 3-((4-(pentyloxy)-2-hydroxybenzylidene)amino)-2-chlorobenzoate (1b): IR (KBr) $v_{\text {max }}$ : 3186, 2951, 2864, 2218, 1739, 1602, 1512, 1487, 1392, 1344, 1290, 1247, 1219, 1192, 1166, 1107, $748 \mathrm{~cm}^{-1}$; ${ }^{1} \mathrm{H}$ NMR $\left(400 \mathrm{MHz}, \mathrm{CDCl}_{3}\right) \delta 13.46(\mathrm{~s}, 1 \mathrm{H},-\mathrm{OH}), 8.55(\mathrm{~s}, 1 \mathrm{H},-\mathrm{CH}=\mathrm{N}-)$, $7.86(\mathrm{dd}, J=2.0,7.2 \mathrm{~Hz}, 1 \mathrm{H}, \mathrm{ArH}), 7.75$ (d, $J=8.0 \mathrm{~Hz}, 2 \mathrm{H}$, $\operatorname{ArH}), 7.70(\mathrm{~d}, J=8.4 \mathrm{~Hz}, 2 \mathrm{H}, \operatorname{ArH}), 7.67$ (d, $J=8.8 \mathrm{~Hz}, 2 \mathrm{H}$, $\operatorname{ArH}), 7.47$ (d, $J=8.0 \mathrm{~Hz}, 1 \mathrm{H}, \operatorname{ArH}), 7.45$ (dd, $J=2.8,7.6 \mathrm{~Hz}$, $1 \mathrm{H}, \operatorname{ArH}), 7.42(\mathrm{~d}, J=8.0 \mathrm{~Hz}, 1 \mathrm{H}, \operatorname{ArH}), 7.32(\mathrm{~d}, J=8.8 \mathrm{~Hz}$, $2 \mathrm{H}, \mathrm{ArH}), 6.53(\mathrm{dd}, J=2.4,8.8 \mathrm{~Hz}, 2 \mathrm{H}, \mathrm{ArH}), 4.01(\mathrm{t}, 2 \mathrm{H}, J=$ $\left.6.4 \mathrm{~Hz},-\mathrm{OCH}_{2}-\right), 1.84-1.77$ (q, $\left.2 \mathrm{H},-\left(\mathrm{CH}_{2}\right)-\right), 1.48-1.34$ (m, 4H, $\left.-\left(\mathrm{CH}_{2}\right)_{2}-\right), 0.99\left(\mathrm{t}, J=6.8 \mathrm{~Hz}, 3 \mathrm{H},-\mathrm{CH}_{3}\right)$; Anal. calcd for: $\mathrm{C}_{32} \mathrm{H}_{27} \mathrm{ClN}_{2} \mathrm{O}_{4}$ : C, 71.30; H, 5.05; found: C, 71.18; H, 4.99 .

4'-Cyano-[1,1'-biphenyl]-4-yl 3-((4-(hexyloxy)-2-hydroxybenzylidene)amino)-2-chlorobenzoate (1c): IR (KBr) $v_{\max }$ : 3184, 2951, 2856, 2222, 1737, 1600, 1512, 1487, 1386, 1342, 1290, 1215, 1192, 1170, 1112, $746 \mathrm{~cm}^{-1}$; ${ }^{1} \mathrm{H}$ NMR (400 MHz, $\left.\mathrm{CDCl}_{3}\right) \delta 13.43(\mathrm{~s}, 1 \mathrm{H},-\mathrm{OH}), 8.54(\mathrm{~s}, 1 \mathrm{H},-\mathrm{CH}=\mathrm{N}-), 7.85(\mathrm{dd}, J$ = 2.0, 7.2 Hz, 1H, ArH), $7.74(\mathrm{~d}, J=8.4 \mathrm{~Hz}, 2 \mathrm{H}, \mathrm{ArH}), 7.69$ (d, $J=8.8 \mathrm{~Hz}, 2 \mathrm{H}, \mathrm{ArH}), 7.66(\mathrm{~d}, J=8.4 \mathrm{~Hz}, 2 \mathrm{H}, \mathrm{ArH}), 7.45$ (d, $J$ $=8.0 \mathrm{~Hz}, 1 \mathrm{H}, \mathrm{ArH}), 7.33(\mathrm{dd}, J=2.8,8.0 \mathrm{~Hz}, 1 \mathrm{H}, \mathrm{ArH}), 7.39$ (d, $J=8.4 \mathrm{~Hz}, 1 \mathrm{H}, \mathrm{ArH}), 7.31$ (d, $J=8.8 \mathrm{~Hz}, 2 \mathrm{H}, \mathrm{ArH}), 6.53$ (dd, $J=2.0,8.8 \mathrm{~Hz}, 2 \mathrm{H}, \mathrm{ArH}), 4.02\left(\mathrm{t}, 2 \mathrm{H}, J=6.4 \mathrm{~Hz},-\mathrm{OCH}_{2}-\right.$ ), 1.85-1.78 (q, 2H, - $\left.\left(\mathrm{CH}_{2}\right)-\right), 1.49-1.35\left(\mathrm{~m}, 6 \mathrm{H},-\left(\mathrm{CH}_{2}\right)_{3}{ }^{-}\right)$, $0.92\left(\mathrm{t}, J=6.8 \mathrm{~Hz}, 3 \mathrm{H},-\mathrm{CH}_{3}\right)$; Anal. calcd for $\mathrm{C}_{33} \mathrm{H}_{29} \mathrm{ClN}_{2} \mathrm{O}_{4}$ : C, 71.67; H, 5.29; found: C, 71.21; H, 5.21.

4'-Cyano-[1,1'-biphenyl]-4-yl 3-((4-(octyloxy)-2-hydroxybenzylidene)amino)benzoate, (1d): ${ }^{1} \mathrm{H}$ NMR $(400 \mathrm{MHz}$,
$\left.\mathrm{CDCl}_{3}\right) \delta 13.40(1 \mathrm{H}, \mathrm{s},-\mathrm{OH}), 8.59(1 \mathrm{H}, \mathrm{s},-\mathrm{CH}=\mathrm{N}-), 8.08(2 \mathrm{H}$, $\mathrm{d}, J=7.2 \mathrm{~Hz}, \operatorname{ArH}), 7.73(2 \mathrm{H}, \mathrm{d}, J=8.1 \mathrm{~Hz}, \operatorname{ArH}), 7.67(2 \mathrm{H}, \mathrm{d}$, $J=9.0 \mathrm{~Hz}, \operatorname{ArH}), 7.64(2 \mathrm{H}, \mathrm{d}, J=8.7 \mathrm{~Hz}, \operatorname{ArH}), 7.55(1 \mathrm{H}, \mathrm{d}, J$ $=7.6 \mathrm{~Hz}, \mathrm{ArH}), 7.34(2 \mathrm{H}, \mathrm{d}, J=8.4 \mathrm{~Hz}, \mathrm{ArH}), 7.29(2 \mathrm{H}, \mathrm{d}, J=$ $8.7 \mathrm{~Hz}, \mathrm{ArH}), 6.49(2 \mathrm{H}, \mathrm{d}, J=2.4,8.4 \mathrm{~Hz}, \mathrm{ArH}), 3.99(2 \mathrm{H}, \mathrm{t}, J$ $\left.\left.=6.4 \mathrm{~Hz},-\mathrm{O}-\mathrm{CH}_{2}-\right), 1.81-1.28\left(12 \mathrm{H}, \mathrm{m},-\left(\mathrm{CH}_{2}\right)_{6}\right)^{-}\right), 0.87(3 \mathrm{H}, \mathrm{t}$, $-\mathrm{CH}_{3}$ ); Anal. calcd for $\mathrm{C}_{35} \mathrm{H}_{34} \mathrm{~N}_{2} \mathrm{O}_{4}: \mathrm{C}, 76.90 ; \mathrm{H}, 6.27$; found: C, 76.28; H, 6.15.

4'-Cyano-[1,1'-biphenyl]-4-yl 3-((4-(hexyloxy)-2-hydroxybenzylidene)amino)-4-chlorobenzoate (1e): IR ( $\mathrm{KBr}) v_{\max }$ : 3184, 2951, 2856, 2222, 1737, 1600, 1512, 1489, 1381, 1342, $1290,1191,1169,1112,746 \mathrm{~cm}^{-1}$; Anal. calcd for $\mathrm{C}_{33} \mathrm{H}_{29} \mathrm{ClN}_{2} \mathrm{O}_{4}$ : C, 71.67; H, 5.29; found: C, 71.14; H, 5.24.

4'-Cyanobiphenyl-4-yl 3-((4-(hexadecyloxy)-2-hydroxybenzylidene)amino)-4-chlorobenzoate (1f): IR (KBr) $v_{\max }$ : 3184 , 2951, 2856, 2222, 1737, 1600, 1488, 1389, 1290, 1215, 1192, $1170,1112,746 \mathrm{~cm}^{-1}$; Anal. calcd for $\mathrm{C}_{43} \mathrm{H}_{49} \mathrm{ClN}_{2} \mathrm{O}_{4}$ : C, 74.49; H, 7.12; found: C, 74.18; H, 7.02.

\section{Acknowledgements}

The authors wish to thank Prof S. Kumar and Ms. K. N. Vasudha of the Raman Research Institute for DSC spectra. Financial assistance is provided to KU and GV (DST Inspire fellowship) by the Department of Science and Technology and to GM (Maulana Azad fellowship) by the University Grants Commission, New Delhi.

\section{References}

1. Pelzl, G.; Weissflog, W. Mesophase Behaviour at the Borderline between Calamitic and 'Banana-shaped' Mesogens. In Thermotropic liquid crystals; Ramamoorthy, A., Ed.; Springer: The Netherlands, 2007; pp 58-83. doi:10.1007/1-4020-5354-1_1

2. Reddy, R. A.; Tschierske, C. J. Mater. Chem. 2006, 16, 907-961. doi:10.1039/b504400f

3. Takezoe, H.; Takanishi, Y. Jpn. J. Appl. Phys., Part 1 2006, 45, 597-625.

4. Pelzl, G.; Diele, S.; Weissflog, W. Adv. Mater. 1999, 11, 707-724. doi:10.1002/(SICI)1521-4095(199906)11:9<707::AID-ADMA707>3.0.C O;2-D

5. Tschierske, C.; Photinos, D. J. J. Mater. Chem. 2010, 20, 4263-4294. doi:10.1039/b924810b

6. Lehmann, M. Liq. Cryst. 2011, 38, 1389-1405. doi:10.1080/02678292.2011.624374

7. Vorländer, D. Ber. Dtsch. Chem. Ges. B 1929, 62, 2831-2835. doi:10.1002/cber.19290621026

8. Vorländer, D. Ber. Dtsch. Chem. Ges. B 1932, 65, 1101-1109. doi:10.1002/cber.19320650710

9. Akutagawa, T.; Matsunaga, Y.; Yasuhara, K. Liq. Cryst. 1994, 17, 659-666. doi:10.1080/02678299408037337

10. Matsuda, T.; Matsunaga, Y. Bull. Chem. Soc. Jpn. 1991, 64, 2192-2195. doi:10.1246/bcsj.64.2192 
11. Matsuzaki, H.; Matsunaga, Y. Liq. Cryst. 1993, 14, 105-120. doi:10.1080/02678299308027306

12. Niori, T.; Sekine, T.; Watanabe, J.; Furukawa, T.; Takezoe, H. J. Mater. Chem. 1996, 6, 1231-1233. doi:10.1039/jm9960601231

13. Pelzl, G.; Wirth, I.; Weissflog, W. Liq. Cryst. 2001, 28, 969-972. doi:10.1080/02678290110039480

14. Sekine, T.; Takanishi, Y.; Niori, T.; Watanabe, J.; Takezoe, H. Jpn. J. Appl. Phys., Part 2 1997, 36, L1201-L1203.

15. Sekine, T.; Niori, T.; Sone, M.; Watanabe, J.; Choi, S.; Takanishi, Y.; Takezoe, H. Jpn. J. Appl. Phys., Part 1 1997, 36, 6455-6463. doi:10.1143/JJAP.36.6455

16. Walba, D. M.; Körblova, E.; Shao, R.; Maclennan, J. E.; Link, D. R.; Glaser, M. A.; Clark, N. A. Science 2000, 288, 2181-2184. doi:10.1126/science.288.5474.2181

17. Lee, S. K.; Heo, S.; Lee, J. G.; Kang, K.-T.; Kumazawa, K.; Nishida, K.; Shimbo, Y.; Takanishi, Y.; Watanabe, J.; Doi, T.; Takahashi, T.; Takezoe, H. J. Am. Chem. Soc. 2005, 127, 11085-11091. doi:10.1021/ja052315q

18. Dantlgraber, G.; Eremin, A.; Diele, S.; Hauser, A.; Kresse, H.; Pelzl, G.; Tschierske, C. Angew. Chem., Int. Ed. 2002, 41, 2408-2412. doi:10.1002/1521-3773(20020703)41:13<2408::AID-ANIE2408>3.0.CO ;2-M

19. Samulski, E. T. Liq. Cryst. 2010, 37, 669-678. doi:10.1080/02678292.2010.488938

20. Francescangeli, O.; Vita, F.; Ferrero, C.; Dingemans, T. J.; Samulski, E. T. Soft Matter 2011, 7, 895-901. doi:10.1039/c0sm00745e

21. Keith, C.; Lehmann, A.; Baumeister, U.; Prehm, M.; Tschierske, C. Soft Matter 2010, 6, 1704-1721. doi:10.1039/b923262a

22. Shanker, G.; Prehm, M.; Tschierske, C. Beilstein J. Org. Chem. 2012, 8, 472-485. doi:10.3762/bjoc.8.54

23. Francescangeli, O.; Samulski, E. T. Soft Matter 2010, 6, 2413-2420. doi:10.1039/c003310c

24. Speetjens, F.; Lindborg, J.; Tauscher, T.; LaFemina, N.; Nguyen, J.; Samulski, E. T.; Vita, F.; Francescangeli, O.; Scharrer, E. J. Mater. Chem. 2012, 22, 22558-22564. doi:10.1039/c2jm33705c

25. Francescangeli, O.; Stanic, V.; Torgova, S. I.; Strigazzi, A.; Scaramuzza, N.; Ferrero, C.; Dolbnya, I. P.; Weiss, T. M.; Berardi, R.; Muccioli, L.; Orlandi, S.; Zannoni, C. Adv. Funct. Mater. 2009, 19, 2592-2600. doi:10.1002/adfm.200801865

26. Shanker, G.; Nagaraj, M.; Kocot, A.; Vij, J. K.; Prehm, M.; Tschierske, C. Adv. Funct. Mater. 2012, 22, 1671-1683. doi:10.1002/adfm.201101770

27. Picken, S. J.; Dingemans, T. J.; Madsen, L. A.; Francescangeli, O.; Samulski, E. T. Liq. Cryst. 2012, 39, 19-23. doi:10.1080/02678292.2011.631593

28. Lehmann, M.; Köhn, C.; Cruz, C.; Figueirinhas, J. L.; Feio, G.; Dong, R. Chem.-Eur. J. 2010, 16, 8275-8279. doi:10.1002/chem.201001214

29. Seltmann, J.; Müller, K.; Klein, S.; Lehmann, M. Chem. Commun. 2011, 47, 6680-6682. doi:10.1039/c1cc10577a

30. Seltmann, J.; Marini, A.; Mennucci, B.; Dey, S.; Kumar, S.; Lehmann, M. Chem. Mater. 2011, 23, 2630-2636. doi:10.1021/cm200643u

31. Yu, F. C.; Yu, L. J. Chem. Mater. 2006, 18, 5410-5420. doi:10.1021/cm060459d

32. Kang, S.; Saito, Y.; Watanabe, N.; Tokita, M.; Takanishi, Y.; Takezoe, H.; Watanabe, J. J. Phys. Chem. B 2006, 110, 5205-5214. doi:10.1021/jp057307a
33. Fergusson, K. M.; Hird, M. J. Mater. Chem. 2010, 20, 3069-3078. doi:10.1039/B923267B

Adv. Mater. 2007, 19, 211-214. doi:10.1002/adma.200601002

34. Matharu, A. S.; Grover, C.; Komitov, L.; Anderson, G. J. Mater. Chem. 2000, 10, 1303-1310. doi:10.1039/b000128g

35. Weissflog, W.; Dunemann, U.; Findeisen-Tandel, S.; Tamba, M. G.; Kresse, H.; Pelzl, G.; Diele, S.; Baumeister, U.; Eremin, A.; Stern, S.; Stannarius, R. Soft Matter 2009, 5, 1840-1847. doi:10.1039/b819758j

36. Deb, R.; Nath, R. K.; Paul, M. K.; Rao, N. V. S.; Tuluri, F.; Shen, Y.; Shao, R.; Chen, D.; Zhu, C.; Smalyukh, I. I.; Clark, N. A. J. Mater. Chem. 2010, 20, 7332-7336. doi:10.1039/c0jm01539c

37. Yoon, D. K.; Deb, R.; Chen, D.; Körblova, E.; Shao, R.; Ishikawa, K.; Rao, N. V. S.; Walba, D. M.; Smalyukh, I. I.; Clark, N. A. Proc. Natl. Acad. Sci. U. S. A. 2010, 107, 21311-21315. doi:10.1073/pnas.1014593107

38. Nath, R. K.; Sarkar, D. D.; Shankar Rao, D. S.; Rao, N. V. S. Liq. Cryst. 2012, 38, 889-902. doi:10.1080/02678292.2012.689375

39. Sarkar, D. D.; Deb, R.; Chakraborty, N.; Nandiraju, V. S. R. Liq. Cryst. 2012, 39, 1003-1010. doi:10.1080/02678292.2012.689866

40. Osipov, M. A.; Pajak, G. J. Phys.: Condens. Matter 2012, 24, No. 142201.

41. Bates, M. A. Chem. Phys. Lett. 2007, 437, 189-192. doi:10.1016/j.cplett.2007.02.025

42. Gray, G. W.; Harrison, K. J.; Nash, J. A. Electron. Lett. 1973, 9 , 130-131. doi:10.1049/el:19730096

43. Gray, G. W.; Harrison, K. J.; Nash, J. A. Electron. Lett. 1973, 9 , 616-617. doi:10.1049/el:19730454

44. Sadashiva, B. K.; Reddy, R. A.; Pratibha, R.; Madhusudana, N. V. Chem. Commun. 2001, 2140-2141. doi:10.1039/b106084h

45. Sadashiva, B. K.; Reddy, R. A.; Pratibha, R.; Madhusudana, N. V. J. Mater. Chem. 2002, 12, 943-950. doi:10.1039/b109546c

46. Murthy, H. N. S.; Sadashiva, B. K. Liq. Cryst. 2004, 31, 567-578. doi:10.1080/02678290410001666093

47. Reddy, R. A.; Sadashiva, B. K. J. Mater. Chem. 2004, 14, 310-319. doi:10.1039/B309262C

48. Radhika, S.; Sadashiva, B. K.; Pratibha, R. Liq. Cryst. 2010, 37, 417-425. doi:10.1080/02678291003632645

49. Ostrovskii, B. I.; Rabinovich, A. Z.; Sonin, A. S.; Sorkin, E. L.; Strukov, B. A.; Taraskin, S. A. Ferroelectrics 1980, 24, 309-312. doi:10.1080/00150198008238661

50. Hallsby, A.; Nilsson, M.; Otterholm, B. Mol. Cryst. Liq. Cryst. 1982, 82, 61-68. doi:10.1080/01406568208070160

51. Otterholm, B.; Nilsson, M.; Lagerwall, S. T.; Skarp, K. Liq. Cryst. 1987, 2, 757-768. doi:10.1080/02678298708086334

52. Soto Bustamante, E. A.; Yablonskii, S. V.; Ostrovskii, B. I.; Beresnev, L. A.; Blinov, L. M.; Haase, W. Liq. Cryst. 1996, 21, 829-839. doi:10.1080/02678299608032899

53. Blinov, L. M. Liq. Cryst. 1998, 24, 143-152. doi:10.1080/026782998207677

54. Pelzl, G.; Eremin, A.; Diele, S.; Kresse, H.; Weissflog, W. J. Mater. Chem. 2002, 12, 2591-2593. doi:10.1039/b206236d

55. Weissflog, W.; Sokolowski, S.; Dehne, H.; Das, B.; Grande, S.; Schroder, M. W.; Eremin, A.; Diele, S.; Pelzl, G.; Kresse, H. Liq. Cryst. 2004, 31, 923-933. doi:10.1080/02678290410001704982

56. Wirth, I.; Diele, S.; Eremin, A.; Pelzl, G.; Grande, S.; Kovalenko, L.; Pancenko, N.; Weissflog, W. J. Mater. Chem. 2001, 11, 1642-1650. doi:10.1039/b100924i

57. Kovalenko, L.; Schroder, M. W.; Reddy, R. A.; Diele, S.; Pelzl, G.; Weissflog, W. Liq. Cryst. 2005, 32, 857-865. doi:10.1080/02678290500231687 
58. Gaussian 09, Revision B.01; Gaussian, Inc.: Wallingford, CT, 2010.

59. Kim, K.; Jordan, K. D. J. Phys. Chem. 1994, 98, 10089-10094. doi:10.1021/j100091a024

60. Stephens, P. J.; Devlin, F. J.; Chabalowski, C. F.; Frisch, M. J. J. Phys. Chem. 1994, 98, 11623-11627. doi:10.1021/j100096a001

61. Leach, A. R. Molecular Modelling - principles and applications, 2nd ed.; Pearson education limited: U. K., 2001.

62. March, N. H. Electron Density Theory of Atoms and Molecules; Academic Press: London, U. K., 1992.

63. Kryachko, E. S.; Ludeña, E. V. Energy density functional theory of many-electron systems; Kluwer: Dordrecht, 1990. doi:10.1007/978-94-009-1970-9

64. Selvaraj, A. R. K.; Weissflog, W.; Friedemann, R. J. Mol. Model. 2007, 13, 907-917. doi:10.1007/s00894-007-0208-5

65. Selvaraj, A. R. K.; Weissflog, W.; Pelzl, G.; Diele, S.; Kresse, H.; Vakhovskaya, Z.; Friedemann, R. J. Phys. Chem. Chem. Phys. 2006, 8, 1170-1177. doi:10.1039/b513934a

66. Weissflog, W.; Naumann, G.; Kosata, B.; Schroeder, M. W.; Eremin, A.; Diele, S.; Kresse, H.; Friedemann, R.; Krishnan, S. A. R.; Pelzl, G. J. Mater. Chem. 2005, 15, 4328-4337. doi:10.1039/b508488a

67. Weissflog, W.; Baumeister, U.; Tamba, M.-G.; Pelzl, G.; Kresse, H.; Friedemann, R.; Hempel, G.; Kurz, R.; Roos, M.; Merzweiler, K.; Jákli, A.; Zhang, C.; Diorio, N.; Stannarius, R.; Eremin, A.; Kornek, U. Soft Matter 2012, 8, 2671-2685. doi:10.1039/c2sm07064b

\section{License and Terms}

This is an Open Access article under the terms of the Creative Commons Attribution License

(http://creativecommons.org/licenses/by/2.0), which permits unrestricted use, distribution, and reproduction in any medium, provided the original work is properly cited.

The license is subject to the Beilstein Journal of Organic Chemistry terms and conditions:

(http://www.beilstein-journals.org/bjoc)

The definitive version of this article is the electronic one which can be found at: doi:10.3762/bjoc. 9.4 